\title{
Limbal Allergic Granulomatosis
}

\author{
ALISON C. E. McCARTNEY \\ London
}

\begin{abstract}
Summary
Four limbal diseases characterised by granuloma formation as part of an allergic response are discussed. A series of histological specimens from patients with Wegener's granulomatosis were re-examined. Genuine granulomatous disease at the limbus is rare, only occurring in two patients, whilst secondary, more non-specific limbal active chronic inflammation was more common. Comparisons between this disease, Churg Strauss allergic angiitis, some varieties of Mooren's ulcer and allergic granulomatous nodules were made. The role of the mast cell in promoting this eosinophilic leucocytic mediated group of disease is discussed briefly.
\end{abstract}

The term allergic granuloma of the limbus has been used, as with granuloma generally ${ }^{1}$ rather loosely in the past, so with some trepidation, four disease processes are discussed these are manifested by limbal disease, in which a granulomatous component is discernible but excluding phlyctenular tuberculosis, sarcoid, fungal disease and lepromatous leprosy, but including granulomatous vasculitis. This somewhat idiosyncratic selection will therefore allow discussion of Wegener's granulomatosis, Churg-Strauss allergic angiitis, some types of Mooren's ulcer and the disease called allergic granulomatosis by Ashton $^{2}$ in his Jackson lecture.

\section{Wegener's granulomatosis and limbosceral disease}

Although Wegener's granulomatosis, first described in 1936, is known to present as an ocular disease $\mathrm{e}^{3,4,5,6,7}$ and up to $50 \%$ of patients ${ }^{8}$ will have eye symptoms, there is a heavy preponderance of orbital disease, especially proptosis, as a result of contiguous sinus disease, in all published series. This is similarily observed in a series of sixty patients on the files at the Institute of Ophthalmology since 1956 who were originally diagnosed as having Wegener's or suspected to have the disease, where a large proportion, $47 \%$, had orbital disease, leading to proptosis or ophthalmoplegia. On follow-up some of these patients did not prove to have systemic disease, and although for a time limited Wegener's of the lung, described as a forme fruste, was described in the literature, in essence this is a systemic disease, ${ }^{9}$ which classically has upper and lower respiratory tract symptoms and renal failure due to glomerulonephritis. Histologically identical lesions are however seen in the limited and classical forms of lung disease and Wegener's disease limited to the orbit has been postulated. There are cases in this series which never showed signs of any systemic progression but nevertheless showed identical orbital histology to those cases that did progress or had progressed to generalised disease at the time of the histological examination.

Of the remaining thirty-two cases in this series, eight showed scleritis and four lid or lacrimal sac disease that might be regarded as 
contiguous disease ${ }^{10}$ and eight necrotising scleritis of the type described by Sevel..$^{11}$ Five cases had Mooren's ulcer, (three bilaterally), and two patients had necrotising iritis. One case had sclerokeratouveitis, not associated with orbital disease (and eight limboscleral disease alone). Three patients had retinal or choroidal limited vasculitis. One case had been previously reassigned to the allergic granulomatosis (Ashton) group.

Re-examination was carried out on twentyfour cases from the non-orbital group, including those with Mooren's ulcer, limboscleral disease, sclero-keratouveitis and iritis. Twenty-one globes, including several removed at post-mortem were examined. These reflected the high incidence of death in these patients before the advent of cyclophosphamide therapy ${ }^{12}$ to control the systemic disease, although it has been known for many years that the ocular manifestations, especially limbo-scleral, of the disease are responsive in most instances to steroid therapy.

In this group of twenty-four patients, on available history and histological examin- ation, nine unequivocal cases of Wegener's granulomatosis of classical type were defined. These patients all had positive histories with nasopharyngeal or sinus disease or chronic otitis media, with lung disease and evidence of renal failure: three had post-mortem confirmation of the diagnosis and two biopsies taken in life from naso-pharynx or lung, showing vasculitis and granulomatous disease (Figs. 1 and 2).

Three further patients had probable Wegener's granulomatosis on histology of the eye, further history being unavailable. Six cases showing necrobiotic palisading granulomata of the sclera, without a positive history of appropriate lung, renal or sinus disease, were reclassified into the group of necrotising scleritis or sclerouveitis. ${ }^{11}$ Five other cases were reclassified as scleritis or episcleritis on the grounds of insufficient evidence of Wegener's granulomatosis. One case was found to be a post-operative uveitis.

Wegener's limbal disease varied in morphology; in two instances, granulomatous disease was seen at the limbus, with giant cells

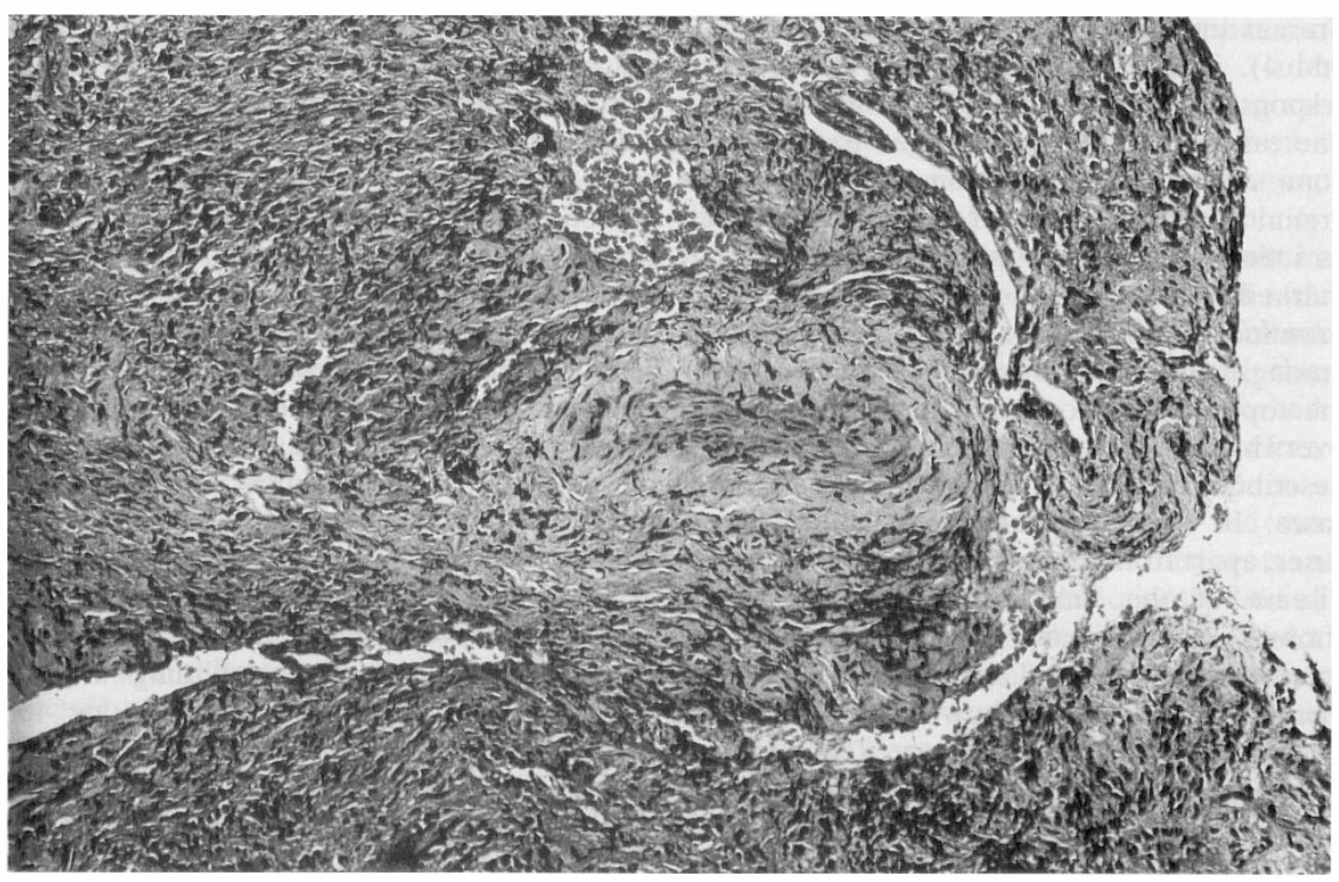

Fig. 1. Occlusive vascular disease in nasal septum of patient with Wegener's granulomatosis. Haematoxylin and eosin $\times 180$. 


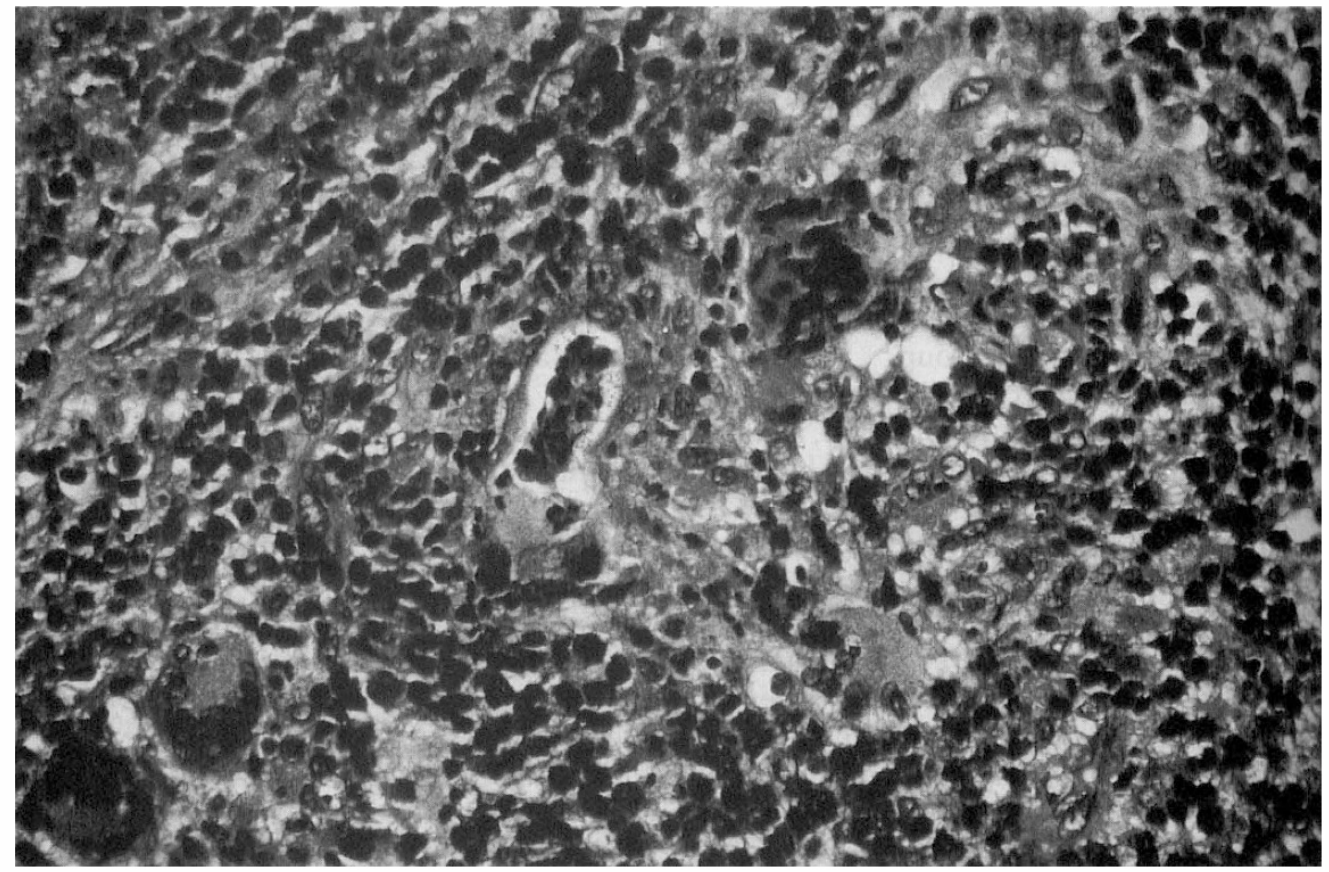

Fig. 2. Granulomatous and eosinophilic infiltrate around necrotising vasculitic focus in nasal septum of patient with Wegener's granulomatosis. Haematoxylin and eosin $\times 450$.

present and vasocentric inflammation (Figs. 3 and 4). The granulomas had developed in response to degradation of collagen and in one case some adjacent collagen had undergone elastotic degeneration, although the granuloma itself was not of the type described as actinic granulomatosis ${ }^{13}$ and vasculitis was marked. Acute necrotising vasculitis with a prominent eosinophilic leucocytic content amongst the lymphocytes, monocytes and macrophages was occasionally seen but the overwhelmingly eosinophilic reaction described by Ashton ${ }^{2}$ was not seen in these cases. In the nine unequivocal Wegener's cases, apart from the two with granulomatous disease at the limbus, three others also showed ulceration and two had vasculitis of small vessels the size of arterioles. Five cases, one with ulceration, showed non-specific, non-granulomatous disease at the limbus which may have been reactive and secondary to the adjacent scleritis. The incidence of limbal granulomatous disease mirrors the situation in the literature where three cases, one each from Fauci, Ferry ${ }^{14}$ and Oishi ${ }^{15}$ had this finding. Straatsma ${ }^{16}$ states however that limboscleral disease is the most common focal manifestation of Wegener's clinically. The vasculitic changes at the limbus itself have also proved difficult to demonstrate. Some authors ${ }^{15}$ think that it is more relevant to examine the course of the anterior ciliary arteries within the rectus muscles and their insertions, than to examine local vessels, believing that an ulcer with the distribution along the limbus depends on occlusion in the anterior ciliary arteries or scleral vessels and subsequentinfarction. In most instances these anterior ciliary vessels are not examined routinely and in this series it was not possible to perform this examination retrospectively. It is interesting to note however that iris segmental necrosis is not a common finding in the patients with Mooren's ulceration due to Wegener's granulomatosis, and this would seem to indicate that selective infarction leading to Mooren's ulcer is more likely to be within the distribution of the anterior episcleral circle than in the anterior ciliary arteries themselves, since segmental iris isch- 


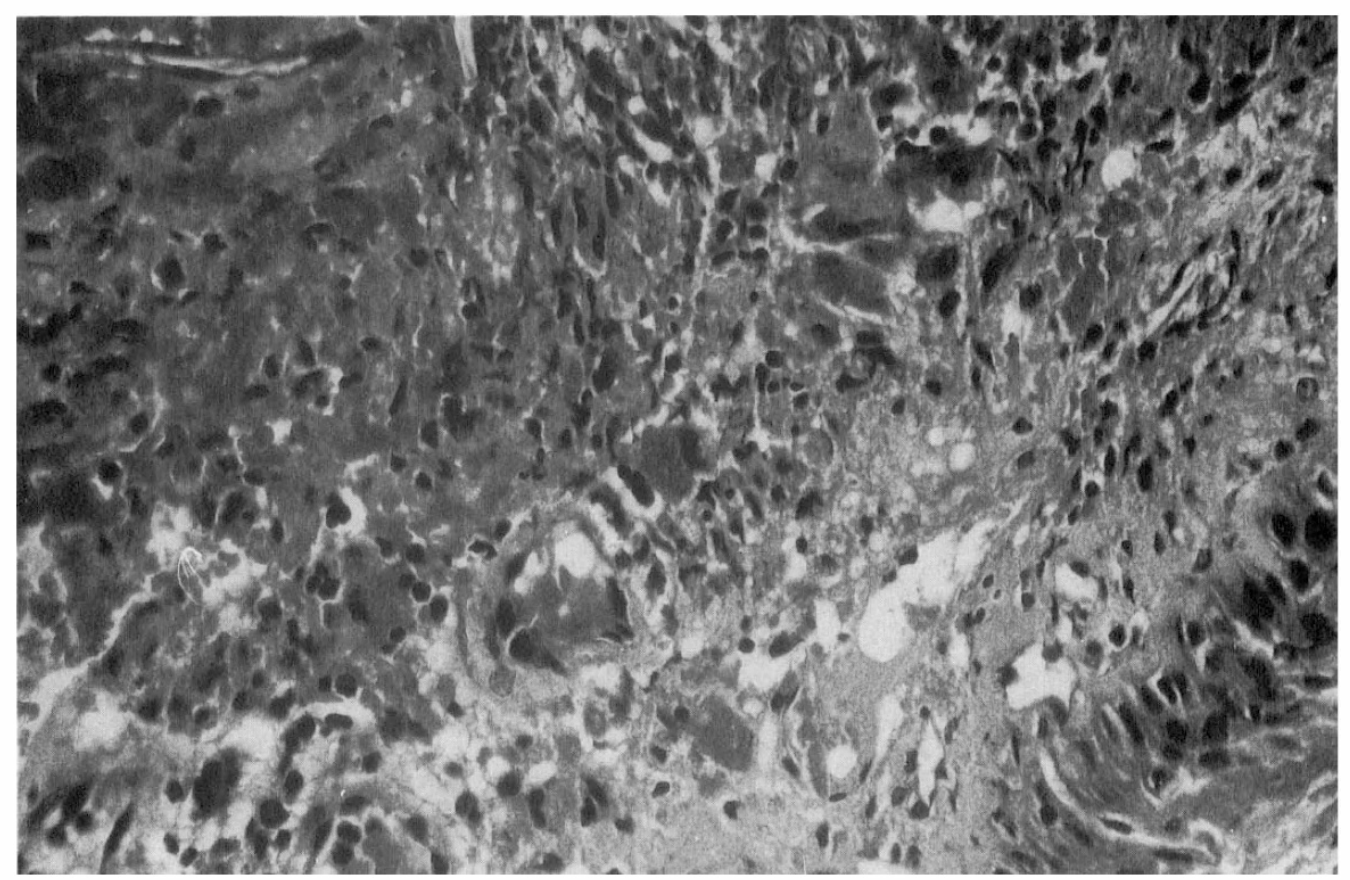

Fig. 3. Giant cell and epithelioid granuloma at limbus (Wegener's) granulomatosis. Haematoxylin and eosin $\times 450$.

aemia and underperfusion of the deeper lying structures would then be more likely to occur. Conversely infarction in the territory of the anterior episcleral arterial circle is likely to lead to selective limbal ischaemia. Frayer ${ }^{17}$ showed a necrotising granuloma in the ciliary body and postulated posterior ciliary arterial occlusion; the resulting ulcer stretched backwards to involve the root of the rectus muscle. Oxygen and glucose can be supplied from the aqueous humour but essential amino acids for maintenance of collagen can only be supplied by the blood stream. ${ }^{15}$

\section{Allergic granulomatosis of Churg-Strauss; allergic angiitis, and the limbus}

In 1951 Churg and Strauss ${ }^{18}$ described thirteen patients with severe asthma who developed a systemic vasculitis of slightly larger vessel type $^{19}$ with a marked tissue and blood eosinophilia and granuloma formation in the lung; ${ }^{20}$ subsequently there have been a few reports in the literature of ocular involvement in this disease. These reports have included conjunctival nodule formation with second- ary amyloidosis, ${ }^{21}$ uveoscleritis, ischaemic optic neuropathy and retinitis and papilloedema ${ }^{22}$ and a single case of marginal ulcer. ${ }^{23}$ None of these reports included histopathological material from the limbus. During this review of material I was unable to identify such a case in our files; two of the patients in the Wegener's series had asthma treated with steroids but neither showed a blood eosinophilia of the level associated with this disease and one patient, with a marked eosinophilia at $28 \%$, was rediagnosed before this survey and was included in Ashton's group of allergic granulomata, ${ }^{2}$ he did not have a severe systemic disease. One woman with orbital disease who subsequently died of her necrotising granulomatosis but who had a blood eosinophilia of $16 \%$ might be a suspect but in all other respects she fulfilled the criteria for Wegener's granulomatosis. It is possible that the treatment of the asthma with systemic steroids prevents eye disease of the type and severity seen in Wegener's disease from developing or it is also possible that these patients are usually classified into the 


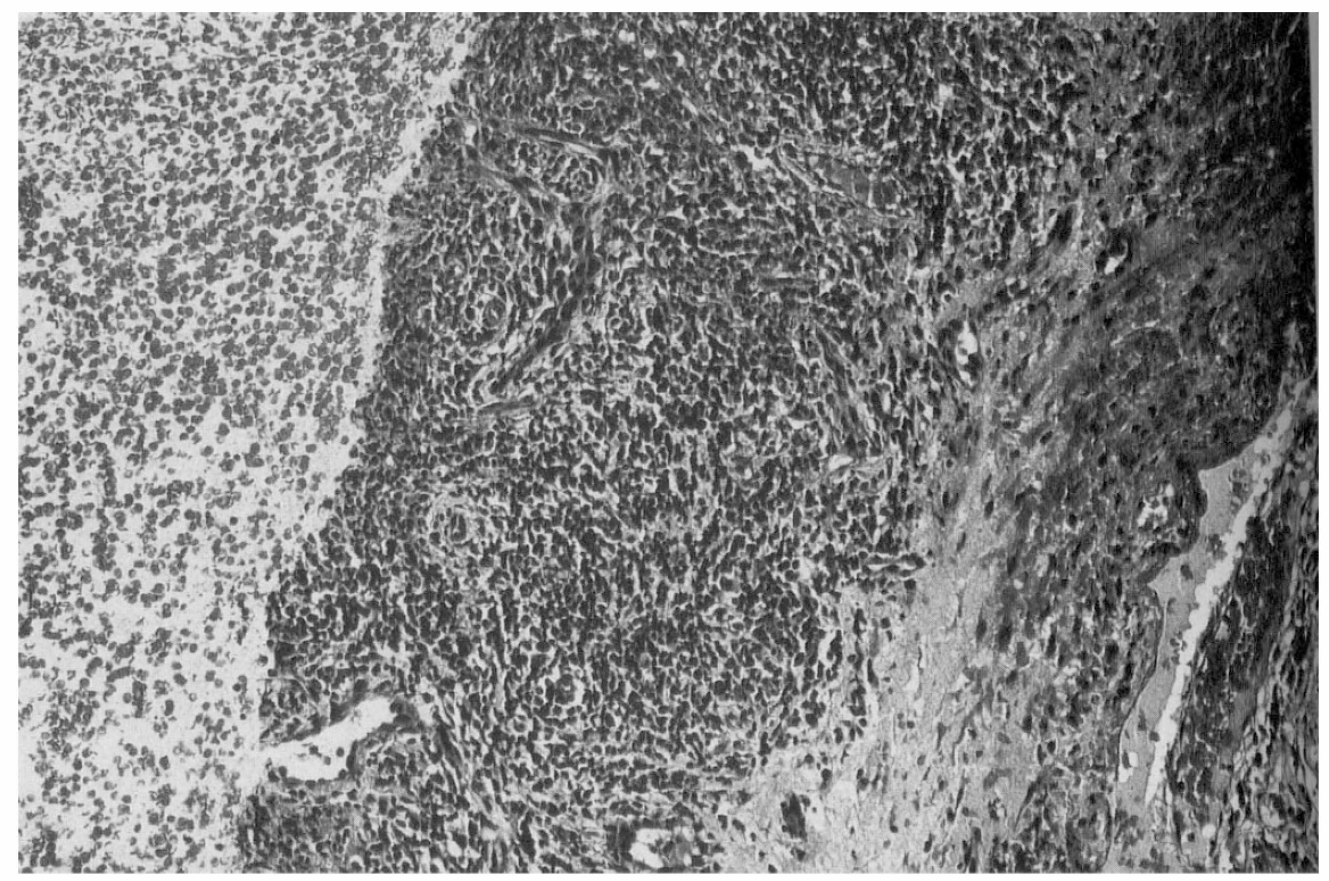

Fig. 4. Vasocentric focus of active chronic inflammation adjacent to granuloma at the limbus. (Wegener's granulomatosis). Haematoxylin and eosin $\times 180$.

polyarteritis nodosa (PAN) group of patients on clinical symptomology especially in the patients with Mooren's ulcer, (patients with PAN were not included in this review). The vascular lesion of allergic angiitis is said to be distinguishable from PAN by Churg himself ${ }^{9}$ and in lung morphology consists of fibrinoid necrosis of muscular arteries with or without capillary and venous involvement. In addition there is massive tissue eosinophilia, foci of necrosis and macrophagic infiltration with evolution of epithelioid cells and multinucleated giant cell formation. Although the difference theoretically should be observable at the limbus, the small number of cases makes such an assumption problematic. Both Wegener's and allergic angiitis fall into the group of necrotising vasculitis with fibrinoid necrosis. Classification in terms of involved vessel size $\mathrm{e}^{24}$ is common and in the eye, small vessel disease, except for the muscular arterial involvement described by Austin, ${ }^{15}$ seems more common. Fibrinoid material is known to consist of several different entities, all with the same tinctoral qualities, but whether the deposit is fibrin itself, immunoglobulins, complement, serum proteins or lysed platelets does not seem to depend on the disease as much as the age of the vascular lesion. All these vasculitides seem to have at least some immune complex mediated disease ${ }^{25,26,27}$ and in some cases, as in scleritis ${ }^{28}$ a cell-mediated hypersensitivity vasculitic reaction is also postulated. ${ }^{29}$ Recently an IgG autoantibody against polymorphonuclear leucocytes has been demonstrated in Wegener's granulomatosis. ${ }^{30}$ Intravascular lysis of these cells in circulation, especially if they are marginated would lead to endothelial cell damage. This is particularly likely to occur where flow is static or subject to unusual dynamics, such as occurs at the top of the limbal arcades, where antibody-antigen complexes are known to impact and become incorporated within the vessel wall. In the case of allergic angiitis part of the inflammatory reaction may depend on the degranulation of mast cells ${ }^{31}$ with complement depletion and their eosinophilic chemotractive properties. Since mast cells are commonly found at the limbus, this is an 
attractive proposition both in allergic angiitis and to a lesser extent in Wegener's where there is also a tendency for lesions to occur at surfaces beneath which there are mast cell populations used to marshalling allergic responses to exogenous allergens.

This is less likely to occur in the kidney unless the exciting protein component is being concentrated there. The peripheral cornea is often used by the body as a 'dumping ground' for excess unwanted proteins, such as excess immunoglobulin light chains in monoclonal gammopathy, ${ }^{32}$ or secondary amyloid protein and there is limbal-scleral deposition of abnormal homogenistic acid metabolic residues in onchronosis.

The role of cryoglobulins in immune complex mediated inflammation of blood vessel at the limbus may depend on the cold gradient found there between the well-perfused subconjunctival connective tissue and the stroma of the cornea which is not perfused at all. It is possible that even such a slight temperature difference may encourage deposition of cryoglobulins at this site where they are subsequently incorporated into the vessel wall as subendothelial deposits or alternatively that mast cells are degranulated by cold ${ }^{31}$ and continue the process of inflammation.

\section{Mooren's Ulcer}

Severe marginal ulceration, classified as being a primary ischaemic necrosis by Aronson, ${ }^{33}$ in addition to being seen in Wegener's granulomatosis and polyarteritis nodosa is described in patients with known autoimmune disease such as systemic lupus erythematosis but has also been found in such diverse bacterial diseases as brucellosis, bacillary dysentery and gonorrhea and in association with the arbovirus of dengue. ${ }^{14}$ These with the exception of dysentery, are diseases associated with acute rheumatic-like joint disease and the underlying pathogenesis of the joint and scleral disease may be due to production of a rheumatoid-like circulating factor. Low titres of classical rheumatoid factor are almost ubiquitous in Wegener's granulomatosis ${ }^{26,34}$ but a circulating autoantibody and a Type II reaction may also occur. ${ }^{30}$

Other theories that have been advanced to explain marginal ulceration include localised drying and overproduction of collagenase,${ }^{14}$ in addition to hypersensitivity and localised ischaemia. Several publications have linked Mooren's ulceration in African patients ${ }^{35,36}$ with undiagnosed parasitic infestations, especially with helminthic infections and this bears a strong resemblance to the group of patients with 'bung-eye' or 'bulge-eye' in Uganda, who were thought to have limbal, conjunctival or orbital nodule associated with eyelid oedema as a result of an abnormal response to the eyelid worm, Demodex folliculorum. ${ }^{2}$

Similar phlyctenular nodules were described by some Japanese workers and these and Howard's paper of 1956 were quoted by Ashton. ${ }^{2}$ Howard's patient had a conjunctival granuloma with a massive eosinophilic reaction, including the evolution of Charcot-Leyden crystals, he also had filariasis.

\section{Ashton's allergic granululomatosis}

In 1979 Ashton and Cook described a series of nodules in the eyelid and conjunctiva that were due to the Splendore-Hoeppli phenomenon, eosinophilic amorphous material first described in response to fungal spores and subsequently to the platyhelminth Schistosoma. This is an in vivo antigen-antibody precipitate, in addition to eosinophilic leucocytic debris including Charcot-Leyden crystals and other chronic inflammatory cell debris. The reaction product is not dissimilar to the sort of material described in deposits in Loeffler's disease. Twenty-two cases are described, seven in detail, three appeared at the limbus. Although the appearance of many of the lesions was almost identical only five had unequivocal evidence of helminthic infestation.

These eosinophils may be reacting to raised $\mathrm{IgE}$ in response to parasitic infection but may also be part of a sustained and inappropriate Type I response mediated by mast cells. A similar mechanism has been postulated in the development of the phenomenon known as angiolymphoid hyperplasia with eosinophilia which has been reported in the orbit ${ }^{37}$ and adnexae but not previously at the limbus. One such case exists on the files from a boy from Jerusalem. The disease differs in that there is 
no evidence of granuloma formation, ${ }^{38}$ otherwise the exudates are similar and the vascular proliferation may be seen in the above process if occlusion is seen especially with thrombosis. The determining factor may be the activation of the tissue eosinophils, in a parallel with activation of mast cells, since it is known that the cationic proteins liberated by the activated eosinophil and protein $\mathrm{X}^{39}$ are toxic to cells and tissues and this may promote necrosis and hence granuloma formation. A form of eosinophilic instability, with tendency to degranulate may occur in these patients, akin to inherent mast cell instability in patients with atopy.

Churg9 quotes Liebow's assertion that it is time to contract the expanding universe of eponyms and urges us to examine the underlying pathogenetic mechanisms in this group of diseases where much is similar but the differences remain.

\section{References}

${ }^{1}$ Adams DO: The granulomatous inflammatory response: a review. Am J Pathol 1976, 84: 164-91.

${ }^{2}$ Ashton $\mathrm{N}$ and Cook C: Allergic granulomatous nodules of the eyelid and conjunctiva. $A m J$ Ophthalmol 1978, 87: 1-28.

${ }^{3}$ Cogan DG: Corneoscleral lesions in periarterits nodosa and Wegener's granulomatosis. Trans Am Ophthalmol Soc 1955, 53: 321-44.

${ }^{4}$ Fauci AS and Wolff SM: Wegener's granulomatosis: studies in 18 patients and a review of the literature. Medicine 1973, 52: 535-61.

${ }^{5}$ Fauci AS, Haynes BF, Katz P, Wolff S: Wegener's granulomatosis. Ann Intern Med 1983, 98: 76-85.

${ }^{6}$ Bullen CL, Liesegang TJ, McDonald TJ, DeRemee RA: Ocular complications of Wegener's granulomatosis. Ophthalmolopgy 1983, 90: 279-90.

${ }^{7}$ Koyama T, Nobuhiko $M$, Watanabe $Y$, Ojima $M$, Koyama T: Wegener's granulomatosis with destructive ocular manifestations. $A m J$ Ophthalmol 1984, 98: 736-40.

${ }^{8}$ Forster CS: Ocular manifestations of the non-rheumatic acquired collagen vascular diseases. In The Cornea. Scientific Foundations and Clinical Practice. eds Smolin G and Thoft RA. Boston Toronto. Little, Brown \& Co, 1987, pp. 344-66.

${ }^{9}$ Churg A: Pulmonary angiitis and granulomatosis revisited. Hum Pathol 1983, 14: 868-83.

${ }^{10}$ Haynes BF, Fishman ML, Fauci AS, Wolff SM: The ocular manifestations of Wegener's granulomatosis: fifteen years experience and a review of the literature. Am J Med 1977; 63, 131-41.

${ }^{11}$ Sevel D: Necrogranulomatous keratitis. $A m$ J Ophthalmol 1967, 63: 250-55.

${ }^{12}$ Fahey JL, Leonard E, Churg J: Wegener's granulomatosis. Am J Med 1954, 17: 168-79.
${ }^{13}$ Ferry AP, Kaltreider SA, Wyatt DB: Actinic granuloma of the conjunctiva. Arch Ophthalmol 1984, 102: $1200-2$.

${ }^{14}$ Ferry AP and Leopold IH: Marginal (ring) corneal ulcer as presenting manifestation of Wegener's granulomata. Trans Am Acad Ophthalmol Otolaryngol 1970, 74: 1276-82.

${ }^{15}$ Austin P, Green WR, Sallyer DL, Kleinfelter HT, Walsh FB: Peripheral corneal degeneration and occlusive vasculitis in Wegener's granulomatosis. Am J Ophthalmol 1978, 85: 311-17.

${ }^{16}$ Straatsma BR: Ocular manifestations of Wegener's granulomatosis. Am J Ophthalmol 1957, 44: 78999.

${ }^{17}$ Frayer WC: The histopathology of perilimbal ulceration in Wegener's granulomatosis. Arch Ophthalmol 1960, 64: 58-64.

${ }^{18}$ Churg J: Allergic granulomatosis and granulomatous vascular syndromes. Ann Allergy 1963, 21: 619-28.

${ }^{19}$ Weinstein JM, Chui H, Lane S, Corbett J, Towfighi J: Churg Strauss syndrome (allergic granulomatous angiitis). Neuro-ophthalmologic manifestations. Arch Ophthalmol 1983, 101: 1217-20.

${ }^{20}$ Varriale P, Minogue WF, Alfenito JC: Allergic granulomatosis: case report and a review of the literature. Arch Intern Med 1964, 113: 235-40.

${ }^{21}$ Meisler DM, Stock EL, Wertz RD, Khadem M, Chaudhuri B, O'Grady RB: Conjunctival inflammation and amyloidosis in allergic granulomatosis and angiitis (Churg Strauss syndrome). Am J Ophthalmol 1981, 91: 216-9.

22 Cury D, Breakley A, Payne B: Allergic granulomatous angiitis associated with uveoscleritis and papilledema. Arch Ophthalmol 1956, 55: 261-6.

${ }^{23}$ Chumbley LC, Harrison EG, DeRemee RA: Allergic granulomatosis and angiitis (ChurgStrauss syndrome). Report and analysis of 30 cases. Mayo Clin Proc 1977, 52: 477-84.

${ }^{24}$ Alarcón-Segovia D: Classification of the necrotising vasculitides in man. Clin Rheum Dis 1980, 6: 22331.

${ }^{25}$ Shillito EJ, Lehner T, Lesof MH, Harrison DFV: Immunological features of Wegener's granulomatosis. Lancet 1974, i: 281-4.

${ }^{26}$ Howell SB and Epstein WV: Circulating immunoglobulin complexes in Wegener's granulomatosis. Am J Med 1976, 60: 259-68.

${ }^{27}$ Nydegger US and Lambert PH: The role of immune complexes in the pathogenesis of necrotising vasculitides. Clin Rheum Dis 1980, 6: 255-78.

${ }^{28}$ Fauci AS, Haynes BF, Katz P: The specimen of vasculitis. Clinical, pathologic, immunologic and therapeutic considerations. Ann Intern Med 1978, 89: 660-76.

29 Watson PG: Doyne Memorial Lecture. The nature and the treatment of scleral inflammation. Trans Ophthalmol Soc UK 1982, 102: 257-81.

${ }^{30}$ van der Woude FJ, Lobatto S, Premin H, van der Giessen, Ramussen N, Wik A, van Es LA: The T. Autoantibodies against neutrophils and monocytes: tool for diagnosis and marker of disease 
activity in Wegener's granulomatosis. Lancet 1985, i: 425-9.

${ }^{31}$ Soter NA and Austen KR: Pathogenetic mechanisms in the necrotising vasculitides. Clin Rheum dis 1980, 6: 233-53

${ }^{32}$ Garner A and Kirkness CM: Corneal gammopathy. Cornea 1988, 7: 46-9.

${ }^{33}$ Aronson SB, Elliott JH, Moore TE, O'Day D: Pathogenetic approach to therapy of peripheral corneal inflammatory disease. Am J Ophthalmol 1970, 70: 65-90.

${ }^{34}$ Hoekstra JA and Fauci AS: The granulomatous vasculitides. Clin Rheum dis 1980, 6: 373-88.

${ }^{35}$ Majekodunmi AA: Ecology of Mooren's ulcer in Nigeria. Doc Ophthalmol 1980, 49: 211-19.
${ }^{36}$ Trojan HJ: Aetiology and therapy of Mooren's ulcer (author's translation). Klin Monatsbl Augenheilkd 1979, 174: 166-76.

${ }^{37}$ Smith DL, Kincaid MC, Nicolitz E: Angiolymphoid hyperplasia with eosinophilia (Kimura's disease) of the orbit. Arch Ophthalmol 1988, 106: 793-5.

38 Welch NT, Hall PA, Sprague DB: Angiolymphoid hyperplasia with eosinophilia. J Roy Soc Med 1987, 80: 384-5.

${ }^{39}$ Po-Chun T, Holt ME, Denny P, Gibbs AR, Williams BD, Spry CJF: Deposition of eosinophil cationic proteins in granulomas in allergic granulomatosis and vasculitis; The Churg Strauss syndrome. $\mathrm{Br} \mathrm{J}$ Med 1984, 289; 400-2. 